\title{
SURVEY ON THE OCCLUSAL MORPHOLOGY OF THE PERMANENT MAXILLARY MOLARS IN A SAMPLE OF EGYPTIAN POPULATION
}

\author{
Ingy Alsakhawy*, Marwa Muhammad Abd El Hameed ${ }^{* *}$ and Medhat Ahmed Elzainy ${ }^{* * *}$
}

\begin{abstract}
Background: The study of dental morphological characteristics is useful for providing information for phylogenic, anthropological, forensic and genetic studies as well as understanding variations within and among species.

Aim: The aim of the study was to investigate, compare and document the distinctive dental characteristics including (occlusal outlines, number of cusps, groove pattern and presence of T.Carabelli) of permanent maxillary molars in a sample of Egyptian population, this was performed morphologically through study casts inspection.

Materials and Methods: 50 upper study casts models of patients aged above 21 years from the Orthodontic Department of Faculty of Dentistry at Ain Shams University with all maxillary molars teeth present were collected. The maxillary molars on the casts were examined regarding their occlusal morphology (occlusal outlines, number of cusps, groove pattern and presence of T.Carabelli). The collected data were statistically analyzed.

Results: Regarding cusp number and groove pattern of maxillary molars, M1 showed prevalence of $4 \mathrm{H}$ groove pattern while 3 cusps and $U$ groove pattern was the most common pattern for M2 \& M3. Regarding the frequency of molar tubercle (tubercle of carabelli), M1 showed prevalence of type I molar tubercle(depression), while the absence of the molar tubercle was the most common pattern for M2 \& M3. Occlusal outline of M1 showed prevalence of the rhomboidal outline while M2 \& M3 showed prevalence of heart shaped outline. Statistical results showed significant difference between the maxillary molars.

Conclusions: Maxillary first molar (M1) showed mostly 4 cusps and $\mathrm{H}$ groove pattern. Maxillary second molar (M2) and Maxillary third molar (M3) showed prevalence 3 cusps and $U$ groove pattern. Type I molar tubercle (depression) was dominating in M1, while for M2 \&M3 the absence of the molar tubercle was the common pattern. The rhomboidal outline was dominating in M1 while the heart shaped was dominating in M2 \& M3.The morphological characteristics of teeth in a sample of Egyptian population were consistent with those of other studies performed on different populations using similar methodology.
\end{abstract}

KEYWORDS: Tooth morphology, Permanent maxillary molars, Cusp form, groove pattern, occlusal outline, T.Carabelli

\footnotetext{
* Oral Biology, Faculty of Dentistry, Ain Shams University, Cairo, Egypt.

** Assistant Professor, Oral Biology Dept, Faculty of Dentistry, Ain Shams University

*** Professor, Oral Biology Dept, Faculty of Dentistry, Ain Shams University
} 


\section{INTRODUCTION}

The dental elements have specific and similar anatomical features depending on their functions in the oral cavity. Among the structures of the dental arch, the permanent molars are the most complex ones, mainly their occlusal surface, due to their function of food grinding (Picosse et al., 1977).

The occlusal surface patterns in the molars of an individual depend on both intrinsic and extrinsic factors. The individualistic nature of the groove pattern can be used to determine the identity of an individual by the process of comparative identification ( Jyotirmoy et al., 2019).

Maxillary molars are large sized teeth that assist mandibular molars in their function, they play an important morphological rule in gender differentiation. It is important to know the cusps variation and various forms of maxillary molars (Yadav AB et al., 2015). Each cusp has an individual growth pattern and different evolutionary background (Kraus $B S$ et al., 1965).

The patterns of the occlusal surfaces of molars are polygenically conditioned and determined by a combination of allele on two or more sites/loci, and they occur in one of the final stages of molar growth, as a result of the terminal deposition of enamel (Macesic et al., 2003 and Horvath et al., 2014).

The crowns of maxillary molars have four main cusps, namely the paracone (mesiobuccal), protocone (mesiolingual), metacone (distobuccal) and hypocone (distolingual).The cusp pattern scoring system for the maxillary teeth focuses on the presence and size of the hypocone (the distolingual cusp) (Dahlberg 1951, Steele and Bramblett 1988).

Steele and Bramblett classification of the Cusp Pattern in Maxillary Molars :

4 Four well developed cusps
4- Hypocone still a major cusp, but significantly reduced in size.

$3+$ Hypocone reduced in size to a small cuspule.

3 Hypocone absent.

Jyotirmoy et al., 2019 described classification of the groove pattern of maxillary molars as follows:

$\mathrm{H}$ groove pattern

Branched $\mathrm{H}$ groove pattern

$U$ groove pattern

Genaro et al., 2019 described classification according to the Frequency of molar tubercle (tubercle of carabelli ) :

-Absence of molar tubercle

-Type I molar tubercle (depression)

-Type II molar tubercle (small prominence)

-Type III molar tubercle (big prominence)

Only few studies were conducted on the dentition of the Egyptian population dealing with the occlusal morphology.

\section{MATERIAL AND METHODS}

\section{A) Materials used}

\section{Dental study casts}

50 upper study casts models of patients aged above 21 years from the Orthodontic Department of Faculty of Dentistry at Ain Shams University with all maxillary molars teeth present were collected. Individuals with any missing maxillary molars and the molars affected by caries or any other defect or disturbance were excluded from the study. Morphologic traits were observed on the permanent maxillary molars (M1,M2,M3). All observations were carried out under good lighting using dental mouth mirror and a dental explorer (Bell and Ayoub, 2003). 


\section{B) Methods}

\section{Occlusal morphology:}

\section{a) Cusp number and groove pattern:}

Examination of maxillary molars was done on the study cast. Teeth should be free from occlusal and proximal caries. According to Jordan et al., 1992, the cusp was considered as a pronounced projection (elevation) on the occlusal surface of the tooth terminating in a conical, rounded or flat surface. After that, the occlusal pattern of each molar was classified according to the standards of morphological variants of permanent teeth of Arizona State University-Dento Anthropological system (Turner et al.,1991).This was determined after marking the developmental grooves using a pencil .

\section{b) The frequency of tubercle of Carabelli:}

Tubercle of carabelli examined and described according to Genaro et al., 2019 classification into

-Absence of molar tubercle

-Type I molar tubercle (depression)

-Type II molar tubercle (small prominence)

-Type III molar tubercle (big prominence)

c) Occlusal outline:

The geometric outline of the occlusal of maxillary molars was investigated on the study casts. Photographs for the study casts were taken and imported into the computer. For every molar, the occlusal outline was outlined and classified into:

1- Rhombidal (parallelogram) occlusal outline

2- Heart shaped (triangular) occlusal outline

3- Oval occlusal outline

\section{Statistical analysis:}

The data was analyzed statistically using fisher exact test which utilized to compare between unrelated groups collectively and pair wise comparison which was used to compare the same items in different groups (M1, M2 and M3). Descriptive statistics including mean and standard deviation were also done.

\section{RESULTS}

\section{A-Occlusal morphology:}

\section{A.I-Cusp number and groove pattern of maxillary first molar:}

Regarding cusp number and groove pattern of maxillary first molar (M1), 4 cusps and $\mathrm{H}$ groove pattern was the most common pattern (94\%) followed by $3+$ cusps and $\mathrm{H}$ groove pattern (4\%) and the little percentage was 3cusps and $U$ groove pattern (2\%). Results for M1 are shown in fig. (1).

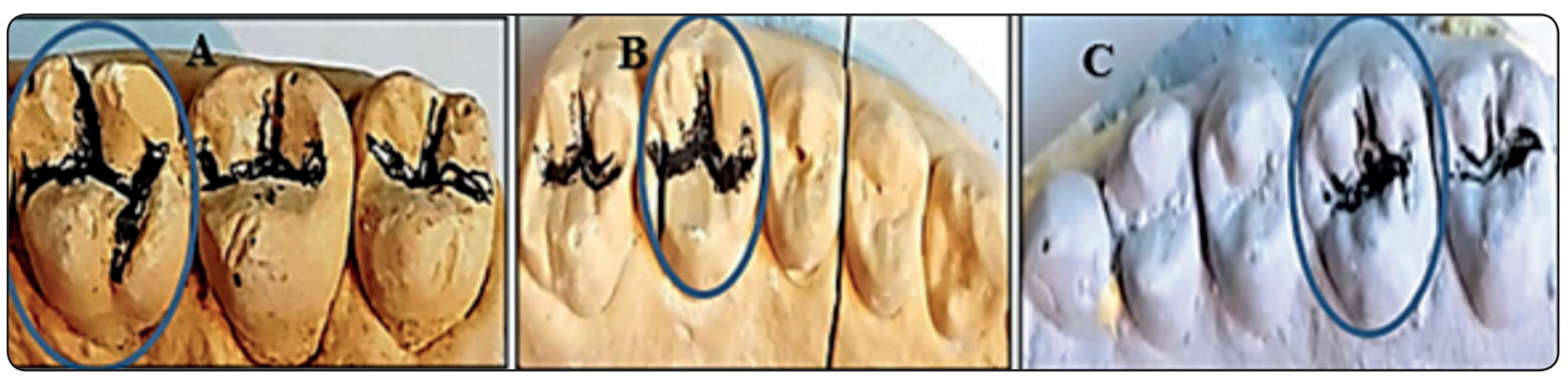

Fig. (1): A photograph of a study casts showing maxillary first molar (M1) with 4 cusps and $\mathrm{H}$ groove pattern occlusal morphology (A), (M1) with 3+ cusps and $\mathrm{H}$ groove pattern occlusal morphology (B) and (M1) with 3 cusps and U groove pattern occlusal morphology (C). 
A.II- Cusp number and groove pattern of maxillary second molar:

Regarding cusp number and groove pattern of maxillary second molar (M2), 3 cusps and $U$ groove pattern was the most common pattern $(60 \%)$ followed by 4 cusps and $\mathrm{H}$ groove pattern (26\%) then 4- cusps and $\mathrm{H}$ groove pattern (12\%) and the little percentage was $3+$ cusps and $\mathrm{H}$ groove pattern (2\%). Results for M2 are shown in fig. (2).

\section{A.III-Cusp number and groove pattern of maxil- lary third molar:}
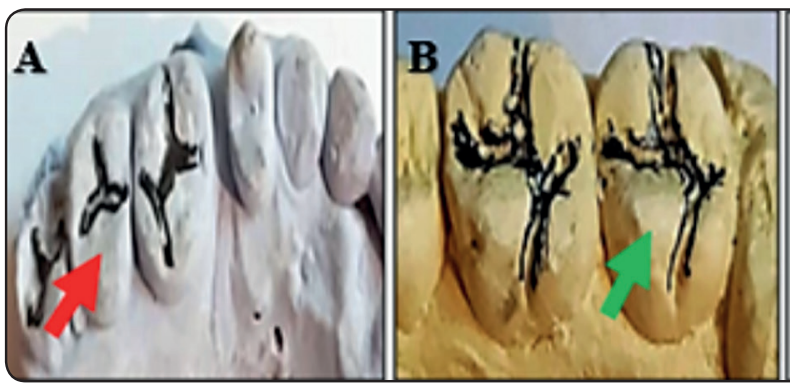

Regarding cusp number and groove pattern of maxillary third molar (M3), 3 cusps and $U$ groove pattern was the most common pattern (98\%) followed by 2 cusps and $U$ groove pattern resembling premolars (2\%). Results for M3 are shown in fig.(3).

Statistical results were shown in [Table (1) and Fig.4].

Regarding similarity between $\mathrm{M} 1$ and $\mathrm{M} 2$ within the same cast, $30 \%$ of the casts $(15 / 50)$ had M1 and M2 resembling each other in which: Both

Fig. (2): A photograph of a study casts showing maxillary second molar (M2) with 3 cusps and U groove pattern occlusal morphology (A), (M2) with 4 cusps and $\mathrm{H}$ groove pattern occlusal morphology (B), (M2) with 4- cusps and $\mathrm{H}$ groove pattern occlusal morphology (C) and (M2) with 3+ cusps and $\mathrm{H}$ groove pattern occlusal morphology (D).
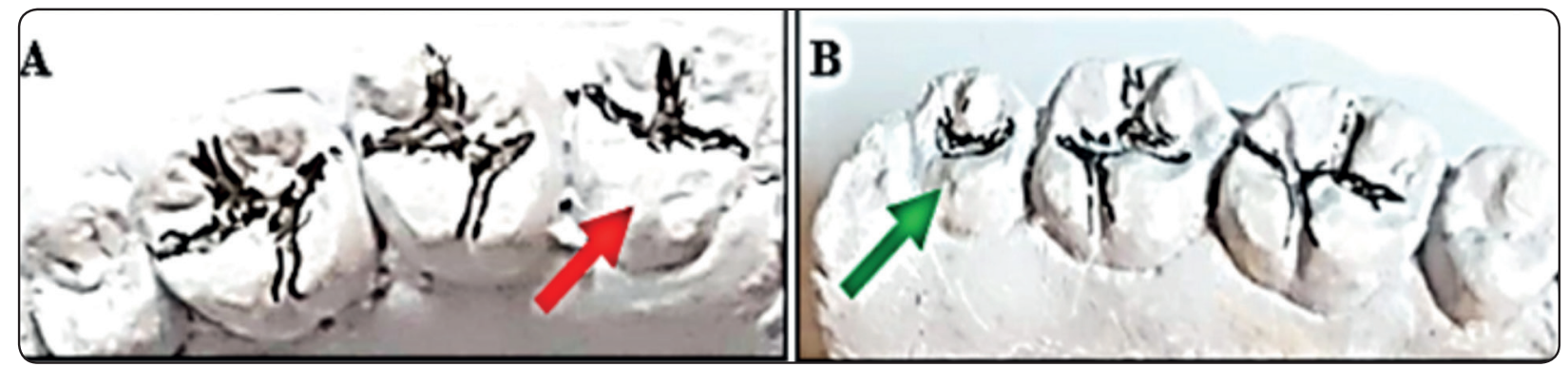

Fig. (3): A photograph of a study casts showing maxillary third molar (M3) with 3 cusps and U groove pattern (A) and (M3) with 2 cusps occlusal morphology (B).

TABLE (1): Cusp number and groove pattern of maxillary molars

\begin{tabular}{|c|c|c|c|c|c|}
\hline $\begin{array}{c}\text { Cusp number and } \\
\text { groove pattern of } \\
\text { maxillary molars }\end{array}$ & $\mathbf{4}$ & $\begin{array}{c}4- \\
\text { Hypocone still a major cusp, } \\
\text { but significantly reduced in size }\end{array}$ & $\begin{array}{c}\mathbf{3 +} \\
\text { Hypocone reduced in } \\
\text { size to a small cuspule }\end{array}$ & $\mathbf{3}$ & $\begin{array}{c}\mathbf{2} \text { cusps as } \\
\text { premolars }\end{array}$ \\
\hline \% of M1 & $94 \%$ & 0 & $4 \%$ & $2 \%$ & 0 \\
\hline \% of M2 & $26 \%$ & $12 \%$ & $2 \%$ & $60 \%$ & 0 \\
\hline \% of M3 & 0 & 0 & 0 & $98 \%$ & $2 \%$ \\
\hline
\end{tabular}


molars were 4 cusps and $\mathrm{H}$ groove pattern which represented $26 \%$ of the casts (13/50), 4 - cusps and $\mathrm{H}$ groove pattern in $2 \%$ of the casts (1/ 50 of casts) and 3 cusps and $U$ groove pattern in $2 \%$ of the casts (1/50) [Table (2) and fig.(4\&5)].

Regarding similarity between M1 and M3 within the same cast, there is no any similarity and there is a great difference between them.

Regarding similarity between M2 and M3 within the same cast, $56 \%$ of the casts (28/50) had M2 and M3 resembling each other in which: Both molars were 3 cusps and $U$ groove pattern. [Table (3) and fig.(6\&7)].

TABLE (2): \% of similarity between M1 and M2 within the same cast regarding cusp number and groove pattern

\begin{tabular}{|l|c|c|c|}
\hline & & $\begin{array}{c}\text { Number of similar M1 and M2 on the } \\
\text { same cast out of 50 casts }\end{array}$ & Similarity (in \%) \\
\hline \multirow{4}{*}{$\begin{array}{l}\text { Cusp number } \\
\text { and groove } \\
\text { pattern }\end{array}$} & 4 cusps \& H groove pattern & 13 & $26 \%$ \\
\cline { 2 - 4 } & 4- cusps \& H groove pattern & 1 & $2 \%$ \\
\cline { 2 - 4 } & 3+ cusps\& H groove pattern & 0 & $0 \%$ \\
\cline { 2 - 4 } & $\mathbf{3}$ cusps\& $U$ groove pattern & 1 & $2 \%$ \\
\cline { 2 - 4 } & Total & 15 & $30 \%$ \\
\hline
\end{tabular}

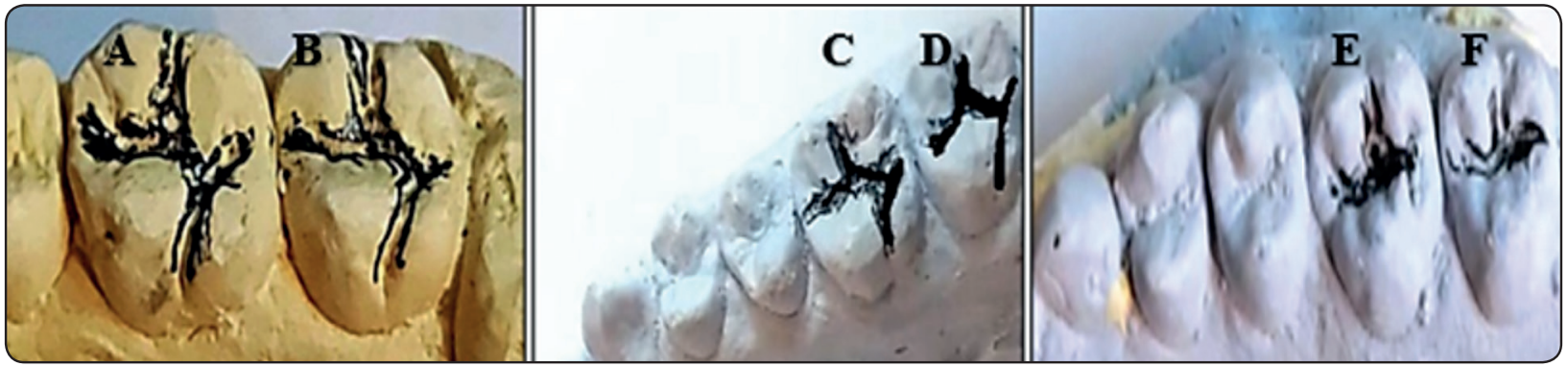

Fig. (4): A photograph of a study cast showing M1 (A) and M2 (B) with 4 cusps and H groove pattern, M1 and M2 (C, D) with 4- cusps and $\mathrm{H}$ groove pattern then $\mathrm{M} 1$ and $\mathrm{M} 2$ (E, F) with 3 cusps and $\mathrm{U}$ groove pattern.

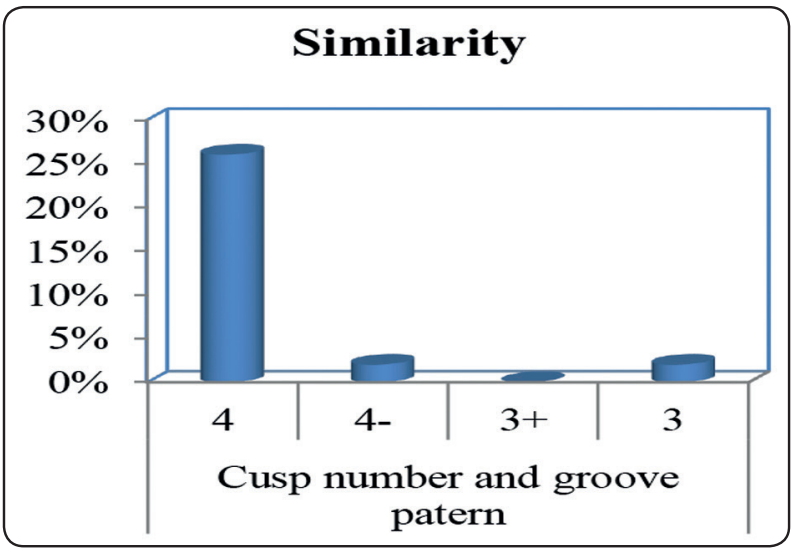

Fig. (5): Bar chart \% of similarity between M1 and M2 within the same cast regarding cusp number and groove pattern.

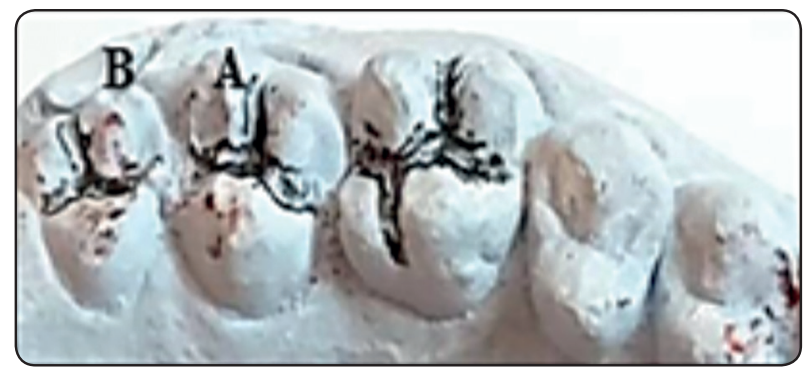

Fig. (6): A photograph of a study cast showing M2 (A) and M3 (B) with 3 cusps and U groove pattern. 
TABLE (3): \% of similarity between M2 and M3 within the same cast regarding cusp number and groove pattern.

\begin{tabular}{|c|c|c|c|}
\hline & & $\begin{array}{c}\text { Number of similar M2 and M3 on the same } \\
\text { cast out of } 50 \text { casts }\end{array}$ & Similarity (in \%) \\
\hline \multirow{5}{*}{$\begin{array}{c}\text { Cusp } \\
\text { number } \\
\text { and groove } \\
\text { patern }\end{array}$} & 4 cusps\& $H$ groove pattern & 0 & $0 \%$ \\
\hline & 4- cusps\& $H$ groove pattern & 0 & $0 \%$ \\
\hline & $3+$ cusps \& $H$ groove pattern & 0 & $0 \%$ \\
\hline & 3 cusps\& $U$ groove pattern & 28 & $56 \%$ \\
\hline & Total & 28 & $56 \%$ \\
\hline
\end{tabular}

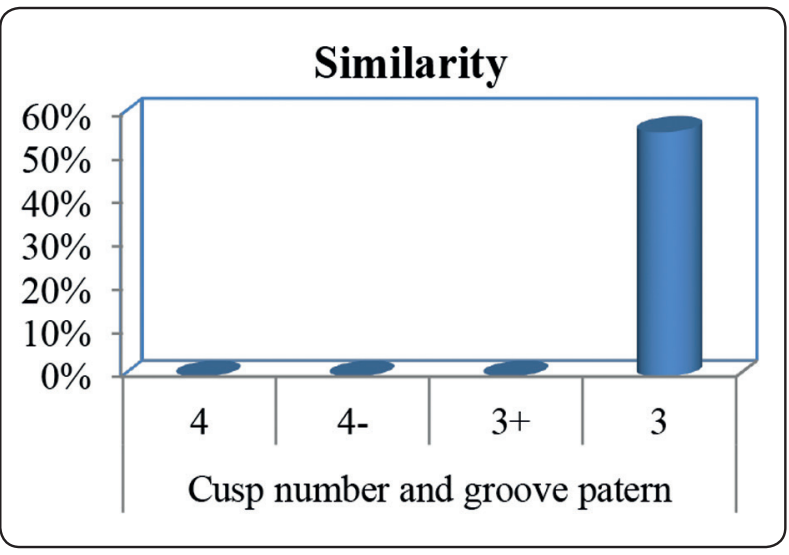

Fig. (7): Bar chart \% of similarity between M2 and M3 within the same cast regarding cusp number and groove pattern.

\section{B) The frequency of molar tubercle (Tubercle of}

\section{Carabelli)}

\section{B.I- The frequency of molar tubercle (tubercle of carabelli) in M1:}

Regarding the frequency of molar tubercle (tubercle of carabelli) in M1, Type I molar tubercle (depression) was the most common (40\%) followed by Type II molar tubercle (small prominence) $(28 \%)$ then $(24 \%)$ characterized by absence of molar tubercle and the little percentage was Type III molar tubercle (big prominence) (8\%). These results are shown in fig. (8\&9).

B.II- The frequency of molar tubercle (Tubercle of Carabelli) in M2:

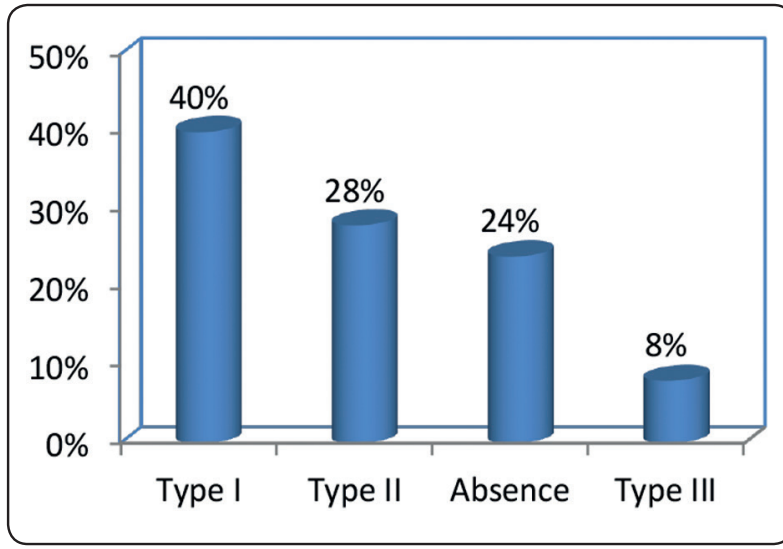

Fig. (8): Bar chart showing Molar tubercle (tubercle of carabelli) in maxillary first molar.

Regarding the frequency of molar tubercle (tubercle of carabelli) in M2, the absence of the molar tubercle was the most common pattern.

\section{B.III- The frequency of molar tubercle (Tubercle of Carabelli) in M3:}

Regarding the frequency of molar tubercle (tubercle of carabelli) in M3, also the absence of the molar tubercle was the most common pattern as M2.

\section{C) Occlusal outline}

\section{C.I-Occlusal outline of maxillary first molar}

Regarding occlusal outline of M1, the most common outline was the rhomboidal which represented by $94 \%$ followed by the heart shaped $(6 \%)$. 


\section{C.II)- Occlusal outline of maxillary second molar:}

Regarding occlusal outline of M2, the most common outline was the heart shaped which represented by $80 \%$ followed by the rhomboidal occlusal outline $(18 \%)$ and the little percentage was oval occlusal outline $(2 \%)$

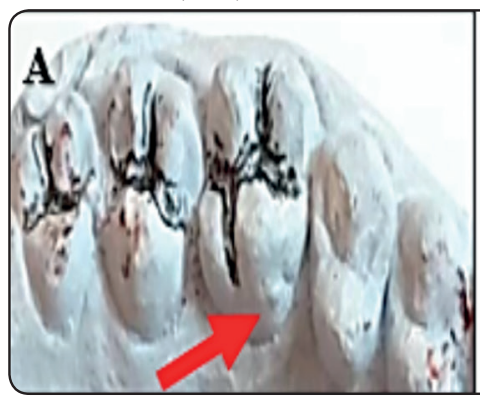

\section{C.III) Occlusal outline of maxillary third molar:}

Regarding occlusal outline of M3, the most common outline was the heart shaped which represented by $98 \%$ followed by oval occlusal outline $(2 \%)$. All results were shown in [Table (4) and fig. (10\&11)]

Fig. (9): A photograph of study casts showing (M1) with Type I molar tubercle (depression) (A), (M1) with Type II molar tubercle (small prominence) (B), (M1) with Type III molar tubercle (big prominence) (C) and (M1) characterized by absence of molar tubercle (D).
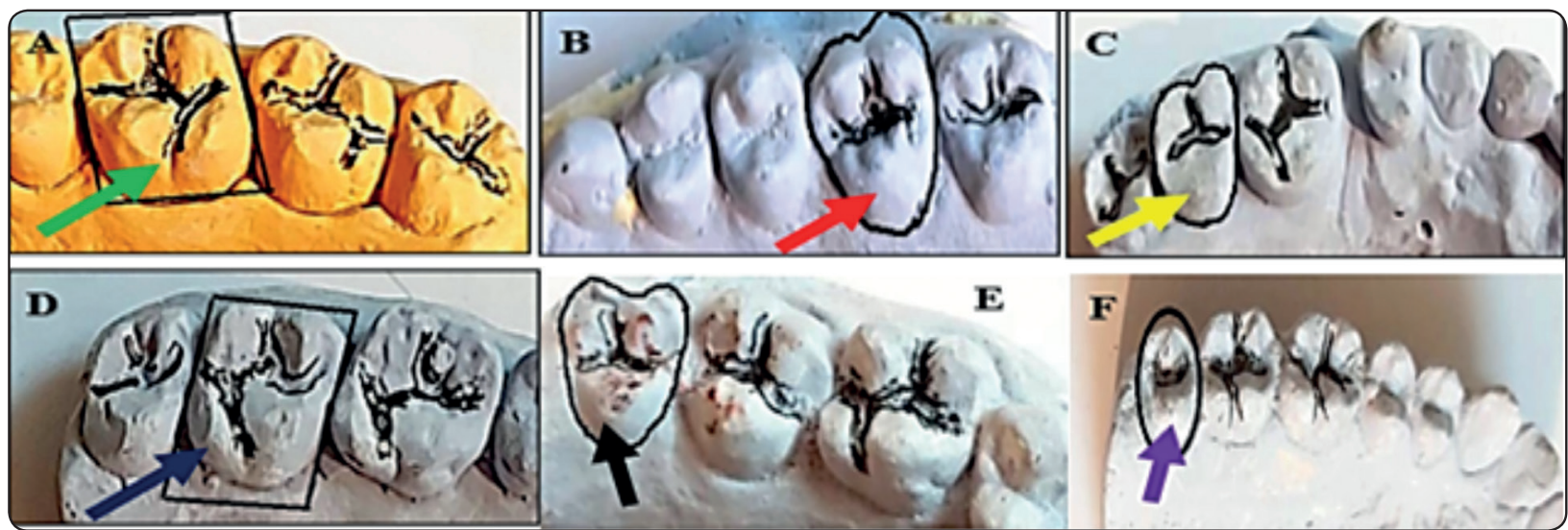

E $\quad$ F

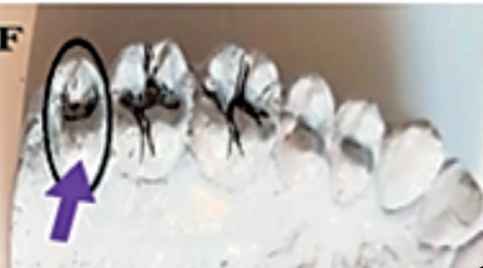

Fig. (10): A photograph of a study cast showing M1 with rhomboidal occlusal outline (A), M1 with heart shaped occlusal outline(B), M2 with heart shaped occlusal outline (C), M2 with rhomboidal shaped occlusal outline (D), M3 with heart shaped occlusal outline (E) and M3 with oval occlusal outline (F).

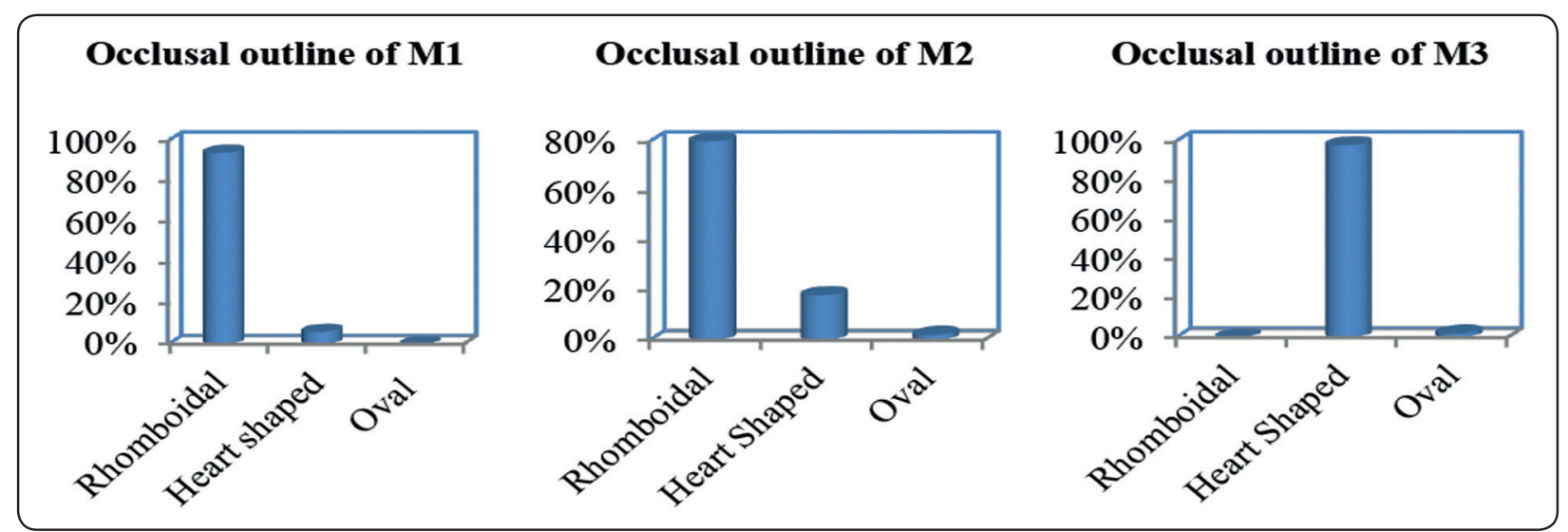

Fig. (11): Bar chart showing occlusal outlines of maxillary molars 
TABLE (4): Occlusal outlines of maxillary molars

\begin{tabular}{|l|c|c|c|}
\hline $\begin{array}{l}\text { Occlusal outline of } \\
\text { Maxillary molars }\end{array}$ & Rhomboidal & $\begin{array}{c}\text { heart } \\
\text { shaped }\end{array}$ & Oval \\
\hline Percentage of M1 & $94 \%$ & $6 \%$ & $0 \%$ \\
\hline Percentage of M2 & $18 \%$ & $80 \%$ & $2 \%$ \\
\hline Percentage of M3 & $0 \%$ & $98 \%$ & $2 \%$ \\
\hline
\end{tabular}

\section{Stastical results :}

Regarding similarity between M1 and M2 within the same cast, $28 \%$ of the casts had M1 and M2 resembling each other in which; both molars were rhomboidal in outline in $22 \%$ of the casts and heart shaped in $6 \%$ of the casts. These results are shown in [Table (5) and fig.(12\&13)].

TABLE (5): \% of similarity between M1 and M2 within the same cast regarding occlusal outline.

\begin{tabular}{|c|c|c|c|}
\hline & & $\begin{array}{l}\text { Number of similar M1 } \\
\text { and M } 2 \text { on the same } \\
\text { cast out of } 50 \text { casts }\end{array}$ & $\begin{array}{c}\text { Similarity } \\
\text { (in } \% \text { ) }\end{array}$ \\
\hline \multirow{4}{*}{ 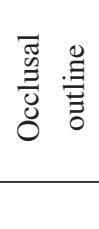 } & Rhomboidal & 11 & $22 \%$ \\
\hline & Heart shaped & 3 & $6 \%$ \\
\hline & Oval & 0 & $0 \%$ \\
\hline & Total & 14 & $28 \%$ \\
\hline
\end{tabular}

Regarding similarity between M1 and M3 within the same cast, there is no similarity between them within the same cast.

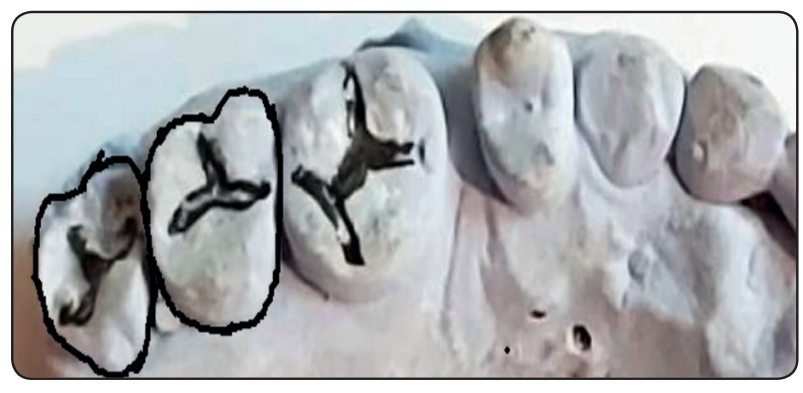

Fig. (14): A photograph of a study cast showing M2 and M3 with heart shaped occlusal outline.

Regarding similarity between M2 and M3 within the same cast, $16 \%$ of the casts $(8 / 50)$ had M2 and M3 resembling each other in which; both molars have heart shaped occlusal outline. These results are shown in [Table (6) and fig.(14\&15)].

TABLE (6): \% of similarity between M2 and M3 within the same cast regarding occlusal outline.

\begin{tabular}{|c|c|c|c|}
\hline & & $\begin{array}{c}\text { Number of similar M2 } \\
\text { and M3 on the same } \\
\text { cast out of } 50 \text { casts }\end{array}$ & $\begin{array}{c}\text { Similarity } \\
\text { (in } \% \text { ) }\end{array}$ \\
\hline \multirow{3}{*}{ 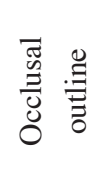 } & Rhomboidal & 0 & $0 \%$ \\
\hline & Heart shaped & 8 & $16 \%$ \\
\hline & Oval & 0 & $0 \%$ \\
\hline & Total & 8 & $16 \%$ \\
\hline
\end{tabular}
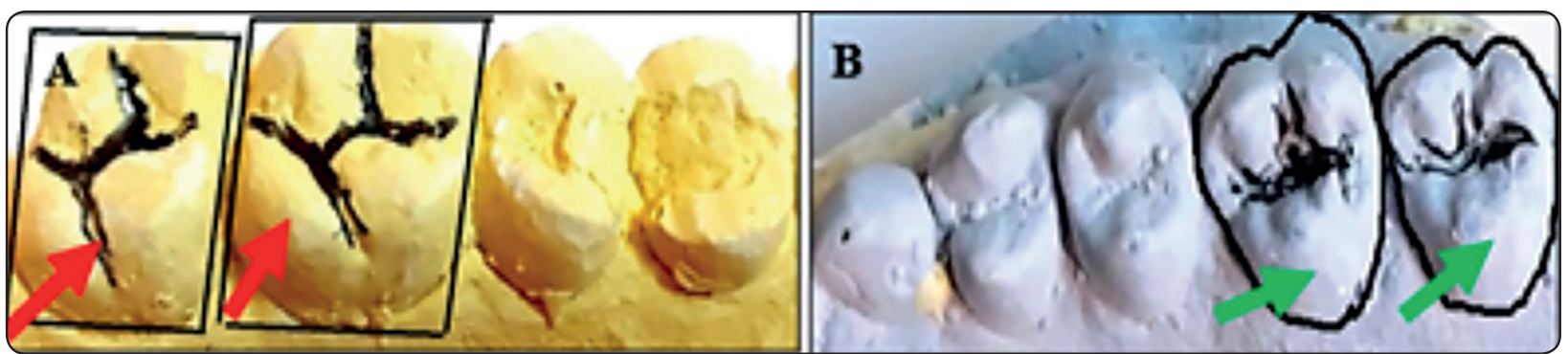

Fig. (13): A photograph of a study cast showing M1and M2 (A) with rhomboidal occlusal outline and M1 and M2 (B) with heart shaped occlusal outline. 


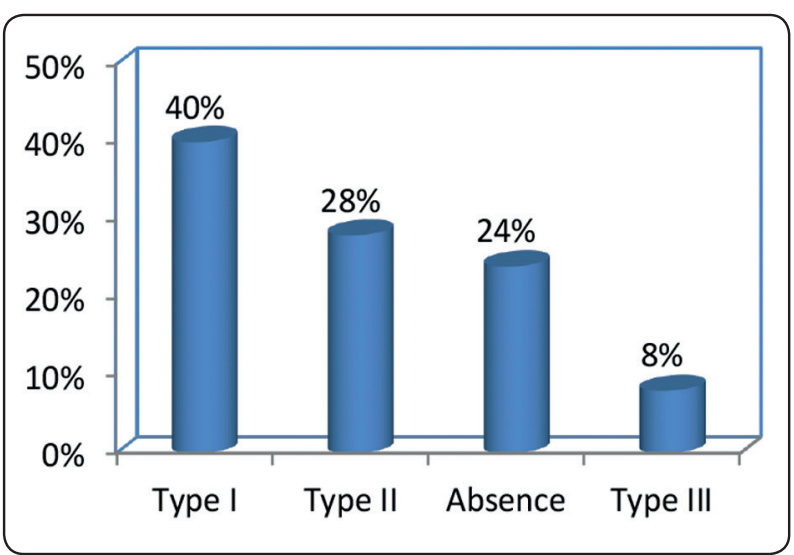

Fig. (15): Bar chart \% of similarity between M2 and M3 within the same cast regarding occlusal outline.

\section{DISCUSSION}

Tooth morphology of the posterior dentition is characterized by distinctive traits with a marked expression in several degrees and different frequencies between humans, thus being useful in comparing and characterizing populations (Gómez-Robles et al., 2007). Studying of the dental morphology implies the process of registration, analysis, and understanding of all the information concerning the coronal morphology of the teeth which appear among populations (Marcovich, 2012).

Ash and Nelson,(2003) documented that knowing the common variations in anatomical and morphological features of each individual tooth can help in various dental treatments such as orthodontic and restorative treatments .

Variations in size, cusp number and groove pattern have been observed in maxillary molars of different populations as much of the human molar's morphological complexity is localized on its occlusal surface (Vaddi et al., 2019). That's why the present study aimed to investigate the occlusal morphology in maxillary molars including cusp number, groove pattern and occlusal outline to determine the identity of an individual by the process of comparative identification (Jyotirmoy et al.2019).

Our study revealed that the cusp number and groove pattern of M1 in a sample of Egyptian population was 4 cusps and $\mathrm{H}$ groove pattern (94\%) , 3+ cusps and $\mathrm{H}$ groove pattern (4\%) \& 3 cusps and $U$ groove pattern (2\%), while that of M2 was 3 cusps and $U$ groove pattern $(60 \%), 4$ cusps and $\mathrm{H}$ groove pattern (26\%) then 4- cusps and $\mathrm{H}$ groove pattern $(12 \%) \& 3+$ cusps and $\mathrm{H}$ groove pattern $(2 \%)$. However, for M3 was 3 cusps and $U$ groove pattern (98\%), 2 cusps and $U$ groove pattern resembling premolars (2\%). No 4 cusps and $\mathrm{H}$ groove pattern was found in $\mathrm{M} 3$ regarding our sample size.

Resemblance with our results was coincident with Yamada et al., (1988) who studied the hypocone variability of human maxillary molars and found that the dominating pattern of M1 was " $4 \mathrm{H}$ " (89\%). Then comes $3+$ cusps and $\mathrm{H}$ groove pattern $(6 \%)$ while the dominating pattern of M2 was 3 cusps and $U$ groove $(66 \%)$ followed by " $4 \mathrm{H}$ " $(24 \%)$ then $4-$ (10\%) and the predominant pattern of M3 was 3 cusps and $U$ pattern which is concomitant with our results.

Moreover, Kalinowska et al., 2003 studied the morphology of third molar and concluded that M3 was dominated by 3 cusps and $U$ pattern $(87 \%)$ which supports our results. Our observations also came in accordance with Yoo et al., (2016), who studied the morphological analysis of upper molars in Korean population, the researchers revealed that " $4 \mathrm{H}$ " pattern was the most prevalent for M1 which also supports our results.

In the current work, within the same cast, only $30 \%$ of the casts had M1 and M2 resembling each other. This was in agreement with Gauta et al., (2010) who found that M2 is more similar in its occlusal morphology to the first maxillary molar which coincides with our results, Regarding the similarity between M1 and M3 within the same cast, our study revealed no similarity and there were great differences between them.

Regarding the frequency of molar tubercle (tubercle of Carabelli), M1 showed prevalence of type I molar tubercle (depression) (40\%), while the 
absence of the molar tubercle was the most common pattern for M2 \&M3.

The etiology of tubercle of Carabelli is still unknown. Most studies agree that the phenotypical appearance of the cusp is genetically determined and there must be a dominant gene responsible for the presence of the cusp (Mavrodisz K. et al., 2007 and Townsend et al., 2009).

Kannapan et al., 2001 studied tubercle of Carabelli as a morphological variation in Indian subpopulation and found that $52.77 \%$ of $\mathrm{M} 1$ exhibited the Carabelli trait and totally absent in M2 \& M3 which resemble our results.Our study findings were contrary to a study conducted on Nigerian population where prevalence of Carabelli trait in M1 was found to be $17.43 \%$ and totally absent in M2\& M3 (Falomo and O.O, 2002).

In accordance with our results were Shethri et al., (2011) who found that the prevalence of Carabelli structure was reported more than one Half of Saudi Population with bilateralism presentation (91.2\%). In a study done by Dilabazkhan et al., (2011) on the prevalence of cusp of Carabelli in permanent teeth in a group from Khyber Pakhtunkhwa (Pakistan), the researchers found that Cusp of Carabelli was present in $29.7 \%$ of M1 and that didn't support our results.

Ameen Khraisat et al., (2011) found that the prevalence of Carabelli's trait on M1 was high among Jordanians $(65 \%)$ and low $(3.8 \%)$ on M2 which supported our results. Katariya $C$ and Jagannathan N., 2017 found that $(62.5 \%)$ of M1 among South Indian population showed Carabelli trait as depression (type I tubercle) and (9.3\%) as big prominence (type III tubercle) and becomes progressively less likely or even absent in M2 \& M3 which was also encountered with our results.

Unlike our study, Qamara et al., 2018 scored frequency of Carabelli trait in M1 of patients visiting a teaching hospital in Mardan (Pakistan) which was $(32 \%)$ of study population with the majority $(56.75 \%)$ appeared as large prominence which disagreed with our results.

In our study M1 showed predominance of the rhomboidal occlusal outline 94\%. M2\&M3 showed predominance of heart shaped outline $80 \%$ and 98\% respectively. $28 \%$ of the casts had M1 and M2 resembling each other within the same cast regarding occlusal outline while there is no any similarity between M1 \& M3 and there are great differences between them. According to Nakayama et al.,2018, the occlusal outline of M1 is rhomboidal. They also documented that M2 is more likely to be heart shaped occlusal outline than M1 and that was concomitant with our results.

It is assumed that this variation are defined polygenetically and its expression is determined by combinations of alleles at two or more loci and are completed in one of the terminal developmental stages of molars, as a result of terminal deposition of enamel. This result in variation of teeth in dentitions of different populations due to genetic and longterm environmental influences (Mosharraf et al., 2010).

\section{CONCLUSIONS}

1. Maxillary first molar (M1) showed prevalence of 4 cusps and $\mathrm{H}$ groove pattern, while Maxillary second molar (M2) and Maxillary third molar (M3) showed prevalence 3 cusps and $U$ groove pattern.

2. Regarding the frequency of the tubercle of carabelli, Type I molar tubercle (depression) was dominating in M1, while for M2 \&M3 the absence of the molar tubercle was the most common pattern.

3. Regarding occlusal outline, the rhomboidal outline was dominating in M1 while the heart shaped was dominating in M2\& M3. 


\section{RECOMMENDATIONS}

1. Studies should be conducted continuously on the dentition of Egyptian population to document evolutionary changes that occur among generations.

2. Similar studies should be conducted to examine other teeth groups in the Egyptian population.

3. Further studies concerning bilateral symmetry and sex differences should be done on human subjects.

4. Moreover, similar studies should be done on samples obtained from different regions in Egypt with possible different sample sizes and by using different techniques.

\section{REFERENCES}

- Ameen Khraisat, Firas Alsoleihat, Karthikeyan Subramani, Sahar T. Taha, Mohammad A., Al-Rabab'ah and Zaid B. AlBitar: Hypocone Reduction and Carabelli's Traits in Contemporary Jordanians, Coll. Antropol. 35 (1): 73-78, 2011

- Ash, M.M. and Nelson, S.J.: Wheeler's dental anatomy,physiology and occlusion, $8^{\text {th }}$ edition, St. Louis: Saunders, pp.273-296, 2003.

- Bell, A. and Ayoub, A.F.: Assessment of the accuracy of a three dimensional imaging system for archiving dental study models. Journal of Orthodontics. (30)219-223, 2003.

- Dahlberg AA: The dentition of the American Indian. The Physical Anthropology of the American Indian. New York: Viking Fund.pp.138-176,1951

- Dilabazkhan, Mcps, M.Phil, Manzar Anwar Khan, Mushtaq Khattak: The prevalence of cusp of Carabelli in permanent teeth in a group from Khyber Pakhtunkhwa, Pakistan. Pakistan Oral \& Dental Journal .31(2):21-26,2011

- Falomo and O.O.: The cusps of Carabelli: frequency, distribution, size and clinical significance in Nigeria. West African Journal of Medicine .21(4):322-324,2002

- Gauta, I., Vazdar, M.A. and Vodanovic, M: Human Molar Crown Traits in Croatian Medieval and Contemporary Populations. Acta Stomatologica Croatica. 44:3-16,2010

- Genaro Luis Eduardo, Gabriely Ferreira, Marcelo Brito Conte, Marcela de Almeida Gonçalves, Ticiana Sidorenko and Oliveira Capote : Morphological Differences between the First and Second Permanent Upper Molars .J Morphol Sci 14801-903, 2019

- Gómez-Robles A, Martinon-Torres M and Bermudez de Castro JM: A geometric morphometric analysis of hominin upper first molar shape. J Hum Evol. 53(3):272-285, 2007

- Horvath JE, Ramachandran GL, Fedrigo O, Nielsen WJ, Babbitt CC and St Clair EM : Genetic comparisons yield insight into the evolution of enamel thickness during human evolution. J Hum Evol 73:75-87,2014

- Jordan, R.E., Abrams, L. and Kraus, B.S.: Kraus's dentalanatomy and occlusion, $2^{\text {nd }}$ edition. St. Louis: Mosby-year book, Inc,pp. 152-167, 1992.

- Jyotirmoy Roy, Muraleedharan M Rohith, Debesh Nilendu and Abraham Johnson: Qualitative assessment of the dental groove pattern and its uniqueness for forensic identification. Journal of forensic dental sciences (JFDS) 11(1) : 42,2019

- Kalinowska Ingrid Różyło, Franciszek Burdan and Tomasz Marchut Folia : Morphology of third molar teeth with incompletely formed apices on the basis of panoramic radiograms 62(2):113-117,2003

- Kannapan, J.G. and S. Sethu: A study on a dental morphological variation. Tubercle of Carabelli. Indian Journal of Dental Research 12(3):.145-149,2001

- Katariya Chanchal \& Dr. Jagannathan Nithya: Prevalence of Cusp of Carabelli in 652 Teeth amongst South Indian Population. International Journal of Multidisciplinary Research and Modern Education.3 (2): 96-100, 2017

- Kraus KB,Jordan RE. The human dentition before birth. Philadelphia:lea and Febiger ,1965

- Macesic, M. and Kaic, Z.: Characteristics of the Occlusal Surfaces of Lower Molars in a Sample of the Croatian Population Acta. Stomat. Croat. 69-73, 2003.

- $\quad$ Marcovich, I., prado, E., Díaz, p., Ortiz, Y., Martínez, C. and Moreno, F.: Dental morphology analysis of Afro-Colombian school children from Villa Rica, Cauca, Colombia. Rev. Fac. Odontol. Univ. Antioq. 24 (1) 37-61, 2012.

- Mavrodisz, K., Rózsa, N., Budai, M., Soós, A., Pap, I. and Tarján, I.: Prevalence of accessory tooth cusps in a contemporary and ancestral Hungarian population. The European Journal of Orthodontics. 29(2)166:169, 2007.

- Mosharraf, R., Ebadian, B., Ali, Z., Najme, A., Niloofar, S. and Leila, K.: Occlusal morphology of mandibular second molars in Iranian adolescents. Indian Journal of Dental Research. 21(1)16-19, 2010 
- Nakayama Mitsuko ,Osamu Kondo, Paula Pesonen, Lassi Alvesalo and Raija La: Influence of long and short arms of X chromosome on maxillary molar crown morphology. Tokyo Journal.60(9):15-21,2018.

- Picosse M.: Anatomia Dentária. 4 ed. São Paulo: Sarvier; 294,1977

- Qamara Wajiha, Mehran Qayumb, Asma Alic and Sana Idreesd: Frequency and trends of cusp of Carabelli in maxillary first molars of patients visiting dental teaching hospital in Mardan, Pakistan. 10(1) 27-29,2018

- Scott G. R., and Irish J. D.: Human Crown and Root Morphology: The Arizona State University Dental Anthropology System. Cambridge: Cambridge University Press, 2017.

- $\quad$ Shethri, S.A.: The prevalence of the Carabelli cusp in selected Saudi population. King Saud University Journal of Dental Sciences 2(1): 13-16,2011

- $\quad$ Steele, D.G and Bramblett C.A.: The anatomy and biology of the human skeleton. College Station, Texas: Texas A\&M University Press, 1988
- Townsend, G., Hughes, T., Luciano, M., Bockmann, M. and Brook A.: Genetic and environmental influences on human dental variation: a critical evaluation of studies involving twins. Arch Oral Biol. J.54 (1): 45-51,2009

- Vaddi, Durga Susmitha, Pallavi, Kattappagari, Kiran Kumar and Reddy Ramana: International Journal of Oral \& Maxillofacial Pathology10 (2): 2-5,2019

- Yamada H, Kawamoto K, Takada S, Hotta Y, Chen JS and Sakai T: Neumerical study of disolingual crown portion on the basis of hypocone variability in upper molars. J Growth 27: $63-74,1988$

- Yadav AB, Angandi PV, Yadav SK. Sex assessement efficacy of permanent maxillary first molar cusp dimensions in Indians .Contemp Clinc Dent.6(4):489-95,2015

- Yoo Hong-Il, Dong-Wook Yang, Mi-Yeon Lee, Min-Seok Kim and Sun-Hun Kim: Morphological analysis of the occlusal surface of maxillary molars in Koreans.Dent J.23(4):11-17,2016 